\title{
DE CONTOS A CURTAS: A FORMAÇÃO DE LEITORES NA ESCOLA
}

\section{FROM SHORT STORIES TO SHORT FILMS: READERS' FORMATION AT SCHOOL}

\author{
Lovani Volmer ${ }^{1}$ \\ Sabrine Elma Heller ${ }^{2}$ \\ Ana Cândida Carvalho ${ }^{3}$ \\ Flavia Brocchetto Ramos ${ }^{4}$
}

\section{RESUMO}

Este estudo discute a importância da literatura na constituição do sujeito e analisa um projeto de leitura, realizado anualmente, desde 2002, com alunos de Ensino Médio, a partir de contos de Machado de Assis, como possibilidade de abordagem do texto literário na escola. Com base especialmente em Candido (1995), Iser (1979), Larrosa (2003) e Petit (2008), o estudo discute fundamentos para um trabalho transformador com a literatura, que seja espaço de cognição, criação e fruição, no qual os alunos-leitores-produtores possam, ao compreenderem o mundo no papel, compreenderem a si mesmos, aos outros e serem criadores de mundos.

PALAVRAS-CHAVE: Leitura; Texto literário; Ensino Médio.

\section{ABSTRACT}

This search discusses the importance of literature in the constitution of the subjects, and it analyzes a reading project, carried out annually, since 2002, with high school students, based on short stories by Machado de Assis, as a possibility of approaching the literary text at school. Underpinned especially on Candido (1995), Iser (1979), Larrosa (2003) and Petit (2008), the study discusses grounds for a transformative work with literature, such as space of cognition, creation and enjoyment, where students producer readers can, by understanding the world in the paper, to understand themselves, the others, and be breeder of new worlds.

KEYWORDS: Reading; Literary text; High School.

\section{INTRODUÇÃO}

A leitura literária possibilita ao leitor decifrar-se, adentrar em outros mundos, sejam eles o mundo real ou aquele criado pelas palavras. Dessa forma, a leitura de narrativas literárias, cuja característica preponderante é ativar a imaginação, possibilita ao leitor navegar por mares não pessoalmente navegados, viver o não vivido, sentir o não sentido, tornando-o, acima de tudo, mais humano e sensível.

A arte, nesse sentido, é a possibilidade de o ser humano, em nosso mundo globalizado e, por isso, cada vez mais igual e de vontades cada vez mais coletivas, habitar outros espaços, percorrer terras alheias, tal qual um caçador, parafraseando Certeau (1994). Contudo, para que essas terras alheias sejam desbravadas, os espaços habitados e a experiência reveladora/criadora de mundos, os textos precisam ser lidos, vividos, sentidos. Como não nascemos leitores, é imprescindível o trabalho com a leitura literária na escola, visando à formação de leitores

\footnotetext{
${ }^{1}$ Universidade Feevale

${ }^{2}$ Instituição Evangélica de Novo Hamburgo - IENH

${ }^{3}$ Escola de Educação Básica Feevale - Escola de Aplicação

${ }^{4}$ Universidade de Caxias do Sul - UCS
} 
autônomos, críticos e criadores, capazes de aceitar, duvidar, concordar, renegar, estranhar, confirmar, transformar o mundo que decifraram.

Com esse objetivo, discutimos, inicialmente, a importância da literatura na constituição do sujeito e, a seguir, analisamos um relato de experiência com abordagem do texto literário na escola visando à formação de leitores, mais especificamente, com alunos do Ensino Médio, a partir da leitura de contos de Machado de Assis.

\section{A leitura literária e a constituição do sujeito}

Ler é um ato de compreensão e alargamento de experiências essenciais ao homem, é a tentativa de o leitor, elaborando relações entre seu conhecimento e as palavras inscritas no texto, construir significados, na tentativa de fugir de uma sociedade que apenas reproduz e copia. Lemos para construir saberes, para fruição, para nos manter informados, para entender o mundo e a nós mesmos.

Nesse sentido, a leitura apresenta, a nosso ver, a capacidade de humanizar, diferenciando o indivíduo leitor de entre os demais, confirmando no homem

aqueles traços que reputamos essenciais, como o exercício da reflexão, a aquisição do saber, a boa disposição para com o próximo, o afinamento das emoções, a capacidade de penetrar nos problemas da vida, o senso da beleza, a percepção da complexidade do mundo e dos seres, o cultivo do humor. (CANDIDO, 1995, p. 249).

A leitura nesses tempos em que somos bombardeados por informações e o pensamento faz-se raro apresenta-se como alternativa que ajuda o leitor a se construir, a imaginar outras possibilidades, a sonhar, a expandir seus horizontes. Para que isso se efetive, porém, não basta identificar o significante isoladamente, é preciso compreender o sentido do texto como um todo; o que se compreende, por exemplo, não são as palavras em sua disposição gráfica, mas o pensamento em movimento em campos semânticos por meio do jogo de várias sintaxes.

Ser leitor, nesse sentido, vai além de possuir um hábito ou atividade regular, é operar um trabalho produtivo, reescrever, alterar sentido, é ser transformado, é o próprio meio pelo qual nos organizamos. Partindo dessa premissa, quando lemos uma história, não só transformamos o texto, mas nós nos transformamos também, pois na

aprendizagem do discurso narrativo e na participação em práticas discursivas narrativas constituímos, aprendemos, melhoramos e modificamos tanto os vocábulos que usamos para a autodescrição como os modos de discurso nos quais articulamos a história de nossas vidas. É na forma de tratar os textos que já existem que adquirimos um conjunto de dispositivos semânticos [...] e um conjunto de dispositivos sintáticos [...] para a autocriação, para narrar-nos no interior desses dispositivos, para fazermo-nos e refazermo-nos através da construção e reconstrução de nossas histórias. Assim, a história da história da vida é a história dos modos como os seres humanos têm construído narrativamente suas vidas. E a história da história de nossas vidas é a história das narrações que temos ouvido e lido e que, de alguma forma, temos estabelecido relação conosco (LARROSA, 2003, p. 618). ${ }^{5}$

As histórias que já lemos e/ou ouvimos ajudam, pois, na constituição do ser que somos, o que faz da leitura uma atividade fundamental à formação do indivíduo. Além disso, têm função libertadora, uma vez que nos possibilitam “[...] escapar, mesmo que seja por um momento, dos

\footnotetext{
5 Tradução livre das autoras: “aprendizaje del discurso narrativo y en la participación en prácticas discursivas narrativas constituimos, aprendemos, mejoramos y modificamos tanto los vocabulários que usamos para la autodescripción como los modos de discurso en los que articulamos la historia de nuestras vidas. Es en nuestro trato con los textos que están ya ahí que adquirimos un conjunto de dispositivos semânticos [...] y un conjunto de dispositivos sintácticos [...] para la autocreación, para narrarnos en el interior de esos dispositivos, para hacernos y rehacernos a nosotros mismos a través de la construcción y la desconstrucción de nuestras historias. Así, la historia de la historia de la vida es la historia de los modos en que los seres humanos han construído narrativamente sus vidas. Y la historia de la historia de nuestras vidas es la historia de las narraciones que hemos oído y leído y que, de algún modo, hemos puesto en relación con nosotros mismos" (LARROSA, 2003, p. 618).
} 
textos que nos modelam, do perigo das palavras que, ainda que verdadeiras, se convertem em falsas uma vez que nos contentamos com elas" (LARROSA, 2003, p. 628). ${ }^{6}$

Para que a obra alcance sua realidade estética, contudo, é preciso que seja lida, transformada para transformar, ganhe vida para dar vida. Pela interação entre texto e leitor, este, a cada leitura, baseando-se em seus conhecimentos, cria, modifica, elabora e incorpora novos conhecimentos em seus esquemas mentais. O texto literário pode, nesse sentido, ser uma forma de conhecimento, pois permite ao leitor, de onde quer que fisicamente esteja, viajar, simplesmente viajar, para lugares próximos ou distantes, o que lhe possibilita, conforme Michele Petit (2008, p. 43),

experimentar um sentimento de pertencer a alguma coisa, a esta humanidade, de nosso tempo ou de tempos passados, daqui ou de outro lugar, da qual pode sentir-se próxima. Se o fato de ler possibilita-se abrir-se para o outro, não é somente pelas formas de sociabilidade e pelas conversas que se tecem em torno dos livros. É também pelo fato de que ao experimentar, em um texto, tanto sua verdade mais íntima como a humanidade compartilhada, a relação com o próximo se transforma. Ler não isola do mundo. Ler introduz no mundo de forma diferente. $\mathrm{O}$ mais íntimo pode alcançar neste ato o mais universal.

Essas ideias de Petit remetem-nos a Candido (1995), quando faz referência ao fato de, na leitura do mundo encenado no papel, o homem se reconhecer como tal, estranhar o diferente, ao mesmo tempo em que amplia as fronteiras de sua compreensão sobre si e sobre o mundo. A linguagem artística possibilita a apropriação de sua riqueza, de sua beleza, da amplitude de seus horizontes, de diferentes percepções de mundo, de universos culturais distintos, uma vez que

é fator indispensável de humanização e, sendo assim, confirma o homem na sua humanidade, inclusive porque atua em grande parte no subconsciente e no inconsciente. [...] Cada sociedade cria as suas manifestações ficcionais, poéticas e dramáticas de acordo com os seus impulsos, as suas crenças, os seus sentimentos, as suas normas [...]. Ela não corrompe nem edifica, portanto; mas, trazendo livremente em si o que chamamos o bem e o que chamamos o mal, humaniza em sentido profundo, porque faz viver (CANDIDO, 1995, p. 243-244).

Ao se reconhecer ou não, ao concordar ou discordar, ao encontrar conforto ou se perturbar com o texto literário, por exemplo, o homem vive aquelas questões e se constitui, cada vez mais e de forma profunda, um ser humanizado. A literatura, contudo, não é lição no sentido doutrinário, não é um ensinamento a ser absorvido ou um saber a ser assimilado. Ela se configura, outrossim, espaço para que o leitor se abra à infinidade de mundos possíveis, fugindo dos totalitarismos, dos reducionismos, da homogeneidade aos quais o mundo real parece conduzir aqueles que não se colocam como sujeitos da palavra. Alberto Manguel (2008) reforça essa possibilidade da literatura ao assegurar que

as histórias não podem nos proteger do sofrimento e do erro, de catástrofes naturais ou humanas, de nossa própria cobiça suicida. [...] as histórias podem nos oferecer consolo para nosso sofrimento e nomes para nossa experiência. As histórias podem nos dizer quem somos, [...] como podem nos ajudar a imaginar um futuro em que, sem finais felizes e confortáveis, possamos continuar vivos e juntos nesta terra tão devastada (MANGUEL, 2008, p. 130-131).

É a literatura, de uma forma simbólica, que vai retratar a humanidade e seus comportamentos, valores e sentimentos, os quais, revelados e discutidos na linguagem literária, não deixam o leitor incólume. A leitura literária, ao possibilitar realidades ainda não pensadas ou vividas, convoca o leitor à participação, o qual, partindo das experiências pessoais anteriores, inclusive de outras leituras, completa - e, ao fazer isso, completa a si mesmo - o espaço poroso da literatura.

Nesse sentido, a literatura não é uma experiência separada da vida, pois permite que digamos o que talvez não saibamos expressar e, ao mesmo tempo, nos fala de maneira mais precisa o que queremos dizer ao mundo e, muitas vezes, a nós mesmos. Além disso, a experiência literária

\footnotetext{
6 Tradução livre das autoras: "escapar, aunque que sea por un momento, a los textos que nos modelan, al peligro de las palabras que, aunque sean verdaderas, se convierten en falsas una vez que nos contentamos con ellas." (LARROSA, 2003, p. 628).
} 
não só nos permite saber da vida pela experiência do outro, mas também vivenciar essa experiência, incorporando a nós aquilo que não somos, mas que temos a possibilidade de ser. Essa multiplicidade de identidades e de realidades que são contadas na narrativa ficcional propõe ao leitor possibilidades de outras existências, de outras verdades, propõe a transgressão. São possibilidades de realidades ainda não vividas, não pensadas, não definitivas. Por isso, a experiência com a leitura literária pode humanizar e libertar. A ela se colocam, conforme Marisa Lajolo (2008, p. 106), “[...] os diferentes imaginários, as diferentes sensibilidades, valores e comportamentos através dos quais uma sociedade expressa e discute, simbolicamente, seus impasses, seus desejos, suas utopias".

O leitor, cuja atividade se constitui na realização de ligações e no estabelecimento de relações, gerando sentidos que variam de acordo com a bagagem leitora de cada um e com a natureza da interação, é, assim, peça-chave quando o assunto é leitura; é ele que atribui "vida" e, portanto, sentido ao escrito. Trata-se, pois, de um exercício de preenchimento de vazios, constantemente ocupados por projeções (ISER, 1979). Essas lacunas, por sua vez, não devem, de forma alguma, ser consideradas como defeito, pois "são um elemento básico para a resposta estética" (ISER, 1999, p. 11) e dão ao leitor a possibilidade de ele estabelecer suas próprias conexões, relacionando os diferentes aspectos do objeto até aquele ponto revelados.

Iser (1999) considera a indeterminação a pré-condição fundamental para a participação do leitor na leitura, pois "só quando se dá ao leitor a oportunidade de participar ativamente é que ele considerará real o texto cuja intenção ele mesmo ajudou a compor" (ISER, 1999, p. 13), ou seja, "o leitor é arrancado de seu assento confortável e mergulhado na situação" (ISER, 1999, p. 19). O estudioso alemão considera, ainda, que, se o texto ficcional se refere à realidade sem se esgotar nessa referência, então, a repetição é um ato de fingir, por meio do qual aparecem finalidades que não pertencem à realidade repetida. Assim, o que retorna ao texto ficcional é uma realidade de todo reconhecível, posta, entretanto, sob o signo do fingimento. Essa premissa também é defendida por Searle (2002), quando se manifesta acerca da ficção, ao considerar que ela não pode ser classificada como fraudulenta, enganosa ou mentirosa, pois "fingir fazer ou ser alguma coisa é envolver-se numa representação, é agir como se estivesse fazendo ou fosse essa coisa, sem nenhuma intenção de enganar" (p. 105).

Pelo reconhecimento do fingir, todo o mundo organizado no texto literário transforma-se em um como se, o que significa que o mundo representado não é propriamente mundo, mas que, por efeito de um determinado fim, deve ser representado como se fosse. Para Iser (1999, p. 8), o texto literário

difere de outras formas de escrita, porque não escreve sobre objetos reais nem os constitui [...], diverge das experiências reais do leitor, na medida em que oferece enfoques e abre perspectivas nas quais o mundo empiricamente conhecido de nossa experiência pessoal aparece mudado.

Como se pode ser denominado de imaginário, porque os atos de fingir se relacionam com o imaginário. Para o estudioso alemão, o sentido do texto não é dado explicitamente, mas se atualiza na consciência imaginativa do leitor. Além disso, o mundo relacionado no texto não se refere a si mesmo e, por seu caráter remissivo, representa algo diverso de si próprio. Os signos icônicos de textos ficcionais têm, pois, a função de produzir significados, não simplesmente designar significados a determinados significantes. $O$ texto atualiza-se apenas no sujeito, a quem cabe imaginar o que os signos, no contexto em que estão inseridos, passaram a excluir.

O mundo concebido é apenas um mundo possível, de um lado, diferenciando-se daqueles mundos de cujo material foi feito e, de outro, oferece uma marcação para uma realidade a ser imaginada, o que, para Iser (1999), pode ser o motivo pelo qual os textos literários são resistentes ao tempo: "não porque representam valores eternos supostamente independentes do tempo, mas porque sua estrutura permite ao leitor continuamente colocar-se dentro do mundo ficcional" (ISER, 1999, p. 41). A leitura, de certa forma, devolve ao texto o processo de realização, por isso o constitui como realidade, o que faz com que a obra se transforme a cada leitura, ou seja, mesmo 
a sua materialidade sendo a mesma, o leitor e a situação de leitura não são mais os mesmos e, portanto, as relações estabelecidas também.

Cabe aqui ressaltarmos que, dadas as possibilidades de conhecimento humano que a literatura proporciona, ela também se oferece como alternativa para a libertação pessoal, o extravasamento e toda a não conformidade com o mundo estabelecido, formatado, engessado em suas perspectivas. Ao percorrer a história da humanidade, muitas são as épocas em que obras literárias foram proibidas, queimadas, condenadas e, por isso mesmo, escondidas, desejadas, lidas à revelia das ordens, comprovando seu poder e importância como expressão humana. Jerome Bruner (1997) reflete sobre a força da literatura, afirmando que talvez seja por isso que os tiranos sintam tanto ódio e medo dos poetas e dos romancistas e, também, dos historiadores. Ódio e medo, aliás, seriam maiores que os que eles sentem dos cientistas, pois, embora estes criem mundos possíveis, não deixam neles espaço para possíveis perspectivas pessoais, alternativas naqueles mundos. Compreender toda essa dimensão da literatura no exercício de suas funções, auxilia o professor a perceber que tem em mãos material riquíssimo para a compreensão humana, aspecto fundamental para uma atuação mediadora e consequente formação integral dos sujeitos.

O ato de ler está, ainda, associado ao tipo de texto, uma vez que não lemos uma notícia jornalística do mesmo modo e com os mesmos objetivos com que lemos um anúncio, mesmo que ambos estejam no mesmo jornal; não lemos um poema da mesma forma e com os mesmos objetivos com que lemos um editorial ou um manual de instruções. Assim, compreendendo a leitura como prática social, corroboramos Magda Soares: "Ler, verbo transitivo, é um processo complexo e multifacetado: depende da natureza, do tipo, do gênero daquilo que se lê, e depende do objetivo que se tem ao ler" (SOARES, 2005, p. 32). Trata-se, pois, de uma ação que nunca pode ser separada das suas finalidades, por isso, quando fazemos menção a essa prática, faz-se necessário clareza acerca de a que leitura estamos nos referindo - no caso deste estudo, à de narrativas literárias no contexto escolar.

\section{Leitura literária e escola: uma relação possível}

A literatura tem, a nosso ver, papel fundamental nos currículos escolares, não como se fosse um "guia de compreensão do ser humano", mas como possibilidade de fruição e de conhecimento. A experiência literária rompe limites, das próprias experiências pessoais, no tempo e no espaço, através da qual também se percebe "quem somos e nos incentiva a desejar e a expressar o mundo por nós mesmos" (COSSON, 2006, p. 17). A busca é de liberdade para o pensar sobre si e sobre o mundo: a transgressão e a alteridade propiciadas pela leitura literária.

Nessa perspectiva, trabalhar com a literatura na sala de aula é compreender a escola como um espaço relevante na formação de leitores, através de práticas pedagógicas comprometidas com o entendimento de que o aluno deva ser sujeito de sua aprendizagem e produtor de conhecimento, e que ela tem a responsabilidade de dar voz à diversidade de pensamento. Além disso, é preciso transcender as abordagens de reprodução de informações ou listagem de elementos narrativos, entre outros aspectos de uma prática tradicional, que também se apresentam como uma forma de conhecimento, mas que não podem se constituir como única. Tarefas como essas podem, se únicos produtos da leitura de obras literárias, ao contrário de aproximar o leitor do texto, acabar por afastálo, uma vez que não se apresentam como criadoras de mundos, não despertam o imaginário, não aguçam os sentidos.

O compromisso educacional transformador, o protagonismo, a identificação das e com as questões humanas são algumas das orientações que encontramos nos documentos gerais para a educação básica e com as quais a leitura literária se relaciona. Para Paulo Freire (1996, p. 27), "a verdadeira leitura me compromete de imediato com o texto que a mim se dá e a que me dou e de cuja compreensão fundamental me vou tornando também sujeito". Dessa forma, acreditamos que uma prática de leitura na escola que se pretende libertadora e transformadora passará, 
necessariamente, por textos literários e, parafraseando Petit (2008, p. 179), como não se entra na leitura ou na literatura como se abraça uma religião, faz-se necessário que seja mediada.

Partindo dessa premissa e defendendo o poder humanizador e transformador da literatura, apresentamos, a seguir, um projeto de leitura que tem, ao longo dos anos, possibilitado aos alunos, a partir da leitura de textos literários, "conduzir para fora, fora do que é único, fora do caminho traçado de antemão, fora do já dito, do já pensado, do já interpretado" (LARROSA, 2003, p. 628) ${ }^{7}$.

\subsection{De contos a curtas: um Projeto que transcende o tempo}

"De contos a curtas" consiste na adaptação de contos de Machado de Assis a curtas-metragens e é desenvolvido, anualmente, desde 2002 até o momento, com alunos do segundo ano do Ensino Médio ${ }^{8}$, em uma escola comunitária da região metropolitana de Porto Alegre, no estado do Rio Grande do Sul (Brasil). Cientes de que o ensino de Literatura e Língua Portuguesa não se restringe à transmissão de regras gramaticais ou ao estudo de características das épocas literárias, buscavam-se alternativas de trabalho para essas aulas. Partiu-se, pois, da certeza de que a leitura literária extrapola a recepção passiva, para configurar-se em uma atividade participativa do leitor, já que a literatura dá espaço à pluralidade de vozes, o que contribui para a formação de sujeitos autônomos, críticos e criadores.

Desde sua criação, o Projeto contou com o envolvimento direto de cerca de 1800 estudantes, que tiveram acesso à leitura literária na escola para além da realização de resumos, fichas de leitura, questionários ou simples apresentações, mas para adentrar no universo da narrativa literária e compreendê-la como produção humana, repleta de experiências, que provoca crítica sobre si mesmo, deixa marcas nas culturas pelas quais atravessa e permite encontrarmos possibilidades de "entender quem somos e aonde chegamos" (CALVINO, 1993, p. 16).

Parece contraditório, muitas vezes, o trabalho na escola com os clássicos, já que as atividades que os envolvem são, em alguns momentos, encaminhadas para culminar em uma avaliação pós-leitura, caracterizando efetivamente a prática leitora na escola como obrigatória. Fornecer razões para a leitura de clássicos, fomentar a descoberta pessoal dessas razões, dar a conhecer outras tantas para que essa leitura se efetive são, portanto, objetivos que a escola deve ter quando coloca o aluno em contato com o cânone.

Não há como pensar em um processo educativo que almeje a formação de leitores proficientes, capazes de fazer suas próprias escolhas, movidos pela busca de crescimento pessoal, de compreensão do mundo que os cerca, pelo desejo de conhecer e explorar novas fronteiras, se dispensarmos as obras clássicas. Elas guardam em suas linhas, nos espaços narrativos - preenchidos ou não - uma identidade cultural, uma herança fundamental das comunidades. Por sua universalidade, falam a todos nós, sobre nossa humanidade, possibilitando algo que é fundamental para que haja leitura: identificação do leitor com o objeto de leitura. E aproveitar essa possibilidade de identificação, que, por motivos já refletidos, precisa de mediação para se configurar, faz parte da tarefa em sala de aula com os clássicos.

Cientes desse papel, o Projeto vem se transformando, sempre no sentido de acompanhar, cada vez mais, as metodologias inovadoras de educação conectadas às demandas do século XXI, mas mantém a sua essência: a leitura de textos literários e sua adaptação para roteiros de curtas-metragens, que, posteriormente, são filmados. Diferentemente de 2002, na atualidade, os alunos leem muito mais online, usam recursos de compartilhamento mais eficientes, exploram aplicativos

\footnotetext{
7 Tradução livre das autoras: "conducir afuera, afuera de lo que uno es, afuera del camino trazado de antemano, afuera de lo ya dicho, de lo ya pensado, de lo ya interpretado”. (LARROSA, 2003, p. 628).

${ }^{8}$ Pareceu-nos adequado desenvolver essa proposta com alunos de segundos anos, pelo fato de já terem tido um ano de estudos literários e, por consequência, apresentarem determinados pré-requisitos para a efetivação do estudo, como entendimento da diversidade de gêneros literários, sobre as funções da linguagem, conhecimento sobre o contexto em que a obra escolhida se encontrava, entre outros.
} 
como Cetltx, que organiza o texto automaticamente, seguindo a estrutura do gênero roteiro, gravam com seus próprios celulares, editam em uma infinidade de aplicativos, conversam em tempo real com roteiristas do outro lado do mundo, entre outras possibilidades.

Porém, independentemente dos recursos utilizados - incluindo aqui o Kindle -, a leitura e a posterior transformação da obra de Machado de Assis acontece de forma efetiva, especialmente quando os alunos descobrem que podem dizer ao mundo, por meio da escrita dos roteiros e, depois, pelos curtas, o que, talvez, não conseguiriam dizer de outra forma. Assim, nesses dezoito anos de Projeto, os mil e oitocentos estudantes envolvidos escreveram quase novecentos roteiros, gravaram mais de cento e quarenta curtas, que chegaram à comunidade escolar por meio de vários canais: blogs, youtube, páginas na internet, instagram, facebook e mostra de curtas, realizada todos os anos na escola. Envolvem-se no Projeto, anualmente, grupos de mais ou menos cinco a seis professores, que acompanham a leitura, a escrita, a gravação, os workshops e a edição dos roteiros, além da culminância do Projeto na noite de estreia, quando os curtas são apresentados, em um salão de atos, ao público. A comunidade escolar também é atingida e tem acesso à produção dos alunos: em 2002, os curtas transformavam-se em fitas de vídeo que eram catalogadas na biblioteca da escola, já nos últimos anos, o youtube é o espaço de armazenamento das produções.

Foram lidas, nesses dezoito anos, inúmeras obras de Machado de Assis, especialmente os contos, entre eles: A Cartomante, O Alienista, Pai contra mãe, O Enfermeiro, O Caso da Vara, Missa do Galo, Jogo do bicho, Conto de Escola, A Chinela Turca, O Espelho. Também tiveram lugar especial nas leituras os romances Dom Casmurro e Memórias Póstumas de Brás Cubas, além de alguns poemas. Entre as leituras, trabalhou-se o poder do texto machadiano, que, segundo Antonio Candido (1995), está em se recobrir com uma fina camada do respeito humano e de boas maneiras, a fim de, por debaixo dela, investigar, desmascarar, descobrir o universo da alma humana. Dixon (1992) corrobora essa ideia quando afirma que, para Machado de Assis, o "mundo" em que há muita coisa maravilhosa está dentro de nós mesmos, na alma. Seus contos, a exemplo de seus romances, desnudam as ações humanas, lançando-lhes um olhar irônico ao revelar as incongruências do homem, suas vaidades, seus pequenos delitos na vida cotidiana, desmascarando a representação de papéis sociais e revelando a profunda diferença entre a aparência e a essência dos indivíduos. Usar tudo isso como ingrediente para contar histórias é falar sobre a humanidade em qualquer tempo, em qualquer lugar. É a alma humana e suas ambiguidades que lhe interessa, as incertezas da existência fomentam sua obra, tornando-a sempre e cada vez mais atual.

Procurou-se investigar, durante as leituras, o realismo enigmático do autor, com tramas e desfechos que põem à mostra as vaidades humanas, as máscaras do cotidiano, desnudando as aparências. Na contramão do pensamento positivista, corrente de pensamento vigente na segunda metade do século XIX, Machado de Assis "satirizará o pensamento enciclopédico, destruirá as hierarquias, glorificará a alinearidade e o subjetivismo e proclamará as verdades relativas" (DIXON, 1992, p. 14). Assim, o mundo fictício machadiano não se apresenta dentro de uma ordem e linearidade rígidos, com causa e efeito necessariamente estabelecidos e determinados, pois há lugar para desordens, acidentes e contradições. Em seus contos, o imprevisível, o inexplicável, os desencontros configuram as relações interpessoais. Ao desdobrar suas histórias nessas nuances múltiplas, permite-se explorar multíplices possibilidades do ser e fazer humano.

A multiplicidade de contos que o autor oferece apresenta também a multiplicidade da alma humana e, por isso mesmo, não há espaço para determinismos moralizantes, enquadres de comportamento ou qualquer outro aspecto que tente dar explicações cabais sobre a humanidade. Pelo contrário, o modo como trata as questões da realidade, os espaços que deixa para serem completados - ou não - pelos leitores, o jogo que estabelece entre o que acontece e o que parece acontecer proporcionam um lugar para ambiguidades, enigmas. Importam as entrelinhas, o que não está dito, ou o que está expresso, mas que pode ser outra coisa, essa é a tensão que conquista o leitor: "Machado tem este dom de fisgar o leitor pela intriga bem arquitetada, intrigando-o com questões não resolvidas" (GOTLIB, 2006, p. 80). 
O escritor não opta pela denúncia frente ao mundo em desatino, pelo julgamento dos absurdos humanos, prefere gracejar com as fraquezas humanas, causando um breve sorriso de "canto de boca", sem a intenção de causar o mesmo efeito de quem conta uma piada. Ao fazer isso, revela e desmascara a alma humana, contrapondo a face que apresenta no convívio social e a que está em seu interior. Em outras palavras, a aparência e a essência.

$\mathrm{Na}$ análise psicológica de seus personagens, não faz julgamentos, não tem intenção moralizante ao revelar as fraquezas humanas, ou ainda purgar culpas. Ele não busca respostas ao comportamento humano, pelo contrário, sua função está na exposição de perguntas, na sua capacidade de suscitar dúvidas sem apontar soluções (DIXON, 1992). No trato irônico das personagens, apresenta um rol das facetas humanas observadas quase que microscopicamente em suas subjetividades, entre elas as mesquinharias e ambições, as hipocrisias, a mediocridade, a dissimulação. Enfim, ao retratar personagens de um Rio de Janeiro de sua época, apresenta um panorama da humanidade, pondo à mostra aspectos surpreendentes que o cotidiano esconde.

Em um estudo aprofundado e atento de sua obra, encontraremos em Machado de Assis um panorama tecido com suas opiniões sobre a humanidade, a sociedade e a história. $\mathrm{Na}$ voz de seus personagens e narradores, alia aspectos relacionados à realidade, ficção e arte literária. Em sua obra, a natureza humana não se presta a um mero descritivismo, é desvendada, no particular e no universal, nas manifestações do íntimo e pessoal e no modo como se apresenta - e aparenta - nas convenções sociais. Voltam os elementos relativos à ambiguidade, à relatividade, à impossibilidade de determinações e de coerência total. Nesse contexto, não se trata de leitura que possa ser considerada "confortável". Seus contos, apesar de manterem-se dentro de expectativas de uma, digamos, exigência moral da época, desnorteiam o leitor, que busca soluções para a trama, respostas a suas dúvidas, ordem para os absurdos. Se a alma humana é contraditória, é isso que interessa a Machado.

Chegar a essa visão sobre a obra de Machado de Assis em sala de aula requer, a nosso ver, muito mais do que enumeração de suas características estilísticas e sua contextualização histórica. É preciso a experiência da leitura de seu texto; nada aproxima mais o leitor de uma obra do que a leitura efetiva. Nesse sentido, são os contos machadianos que revelarão o escritor aos alunos, estimulados a entrar em contato com a universalidade e atualidade de seus textos.

A proposição da leitura de contos de Machado de Assis para posterior adaptação em roteiros de cinema pretendia, pois, além de aproximar os jovens leitores de textos literários e instigá-los à leitura, possibilitar o contato com a obra daquele que é um dos maiores escritores da literatura brasileira e que também pudesse ressoar nos jovens leitores da atualidade. Independentemente da época, do mundo representado, seus contos têm algo a dizer a leitores contemporâneos e, referente ao foco deste estudo, a leitores jovens em idade escolar.

John Gledson (2007) reflete sobre os contos do autor, enfatizando esse caráter atemporal, quando afirma que Machado de Assis

acaba encontrando novas maneiras de falar sobre coisas demasiado embaraçosas para mencionar diretamente. $\mathrm{Na}$ minha opinião, isso ajuda a explicar o êxito destes contos Machado caminhava no fio da navalha, o que lhe deve ter dado, e a seus leitores, uma espécie de excitação; algo que, por incrível que pareça, podemos sentir num mundo bem diverso, o nosso, pois essa sensação está aqui, na linguagem, e suas negaças, nos pormenores, nos atos, nas situações e nos personagens (p. 13).

Para conhecer a obra de Machado de Assis, e aqui se destacam especialmente seus contos, é preciso, sobretudo, lê-la. São as composições narrativas, e sua multiplicidade e riqueza consequentes, que possibilitarão ao leitor em formação conhecer o autor e encontrar o universo que tanto o encantava: a alma humana.

Sendo assim, iniciou-se o Projeto, em 2018 ", pela leitura e estudo coletivo do conto "O Bilhete". O texto foi introduzido pela professora de Língua Portuguesa, que o leu para os alunos

${ }^{9}$ Em 2018, 120 alunos participaram diretamente do Projeto. 
até o momento em que o bilhete é encontrado e instigou-os a pensarem na continuação e finalização da história. A fim de confirmar ou refutar suas hipóteses, na aula de Literatura, os alunos receberam o conto impresso e realizaram, primeiro, uma leitura silenciosa, individual. Depois, juntos, resolveram-se questões de vocabulário e apontaram-se aspectos relevantes da narrativa: quem era o narrador do conto, como ele se colocou na narração, o que fica se sabendo sobre as personagens à medida que se avança na leitura, qual o desfecho e o que se esperava que acontecesse. $\mathrm{Na}$ aula de Sociologia, com base no conto, refletiu-se sobre qual recorte da sociedade era proposto, se era atual ou não, conduzindo reflexões e debates em sala de aula, preparando para o passo seguinte, quando se propôs, em Literatura, um levantamento sobre a vida e a obra do autor, a fim de entender o universo literário em que estava inserido, o que a teoria teria a dizer sobre sua obra, comparando com as impressões dos alunos até então. Essa pesquisa inicial foi realizada em duplas e, no coletivo, com os professores de Literatura e História, em conjunto, construiu-se um mapa conceitual, que ficou exposto em cada uma das salas de aula.

Da leitura acompanhada e que introduziu o estudo sobre a obra do autor, os alunos foram desafiados a ler outros contos. Foram instruídos a ler e, a exemplo da análise coletiva, identificar elementos fundamentais da narrativa, além de averiguar se havia alguma relação com a sociedade atual. Como a ideia era pensar a história lida transposta para um outro gênero, a produção cinematográfica, a leitura foi também motivada pela busca de textos que oferecessem uma boa história a ser contada através de recurso audiovisual. A orientação era ler o máximo de contos possíveis dentro de um determinado prazo - cerca de três semanas - e selecionar um que mais tivesse lhes despertado interesse, qualquer que fosse a natureza dessa escolha. Essas leituras foram extraclasse, em sua maioria, mas, a cada semana, privilegiou-se um período em sala de aula somente para leitura, independentemente do suporte; o importante era que os alunos lessem, que se permitissem adentrar no universo machadiano, nos interstícios narrativos de Machado de Assis. A cada nova descoberta acerca do autor e sua obra, os alunos iam ampliando as informações em um mapa conceitual (Fotos 1 e 2), cujas temáticas foram a tônica das aulas de Filosofia e Sociologia.

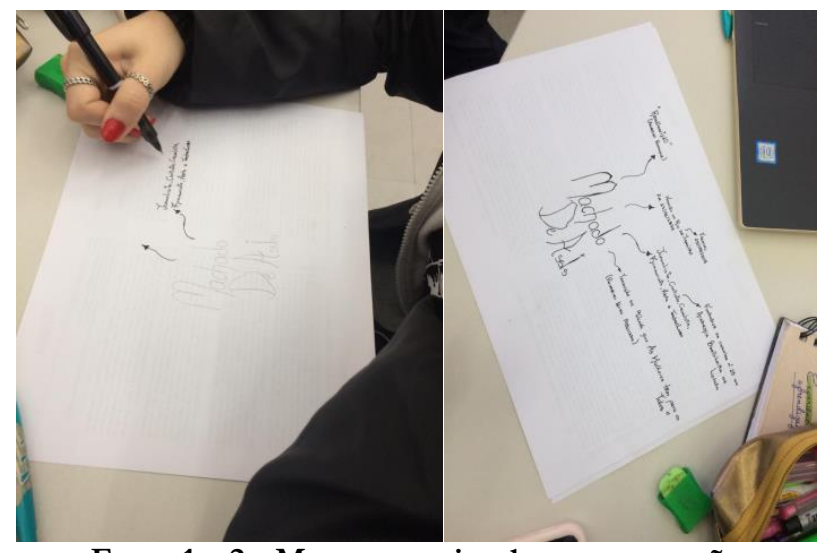

Fotos 1 e 2 - Mapa conceitual em construção Fonte: As autoras

Assim, gradativamente, os alunos do Ensino Médio envolveram-se nas tramas machadianas e, a partir delas, criaram suas histórias, teceram suas tramas e, de leitores, passaram a criadores de mundos, oportunizando, por sua vez, a outros leitores, contato com os mundos por eles criados. E a leitura difícil, normalmente atribuída aos textos de Machado, deu lugar a descobertas: de pessoas, de lugares, de palavras... Importante considerar, ainda, que, além das disciplinas de Literatura e Língua Portuguesa, idealizadoras do Projeto, a inserção de História, Sociologia, Filosofia e Artes possibilitou, a partir da leitura dos contos, um mergulho nas tramas machadianas, de modo que o mundo das narrativas passou a ser o pano de fundo dos estudos linguísticos, históricos, sociológicos, filosóficos, artísticos. Ouvir histórias, representar, ler, analisar narrativas, 
narradores, personagens e comportamentos possibilitou aos alunos não só refletirem sobre os textos machadianos, mas, com base neles, sobre si e o outro e sobre o contexto histórico e social em que estamos inseridos.

Passado o processo de leituras, os alunos foram desafiados a escolher um dos contos de Machado e transformarem-no em roteiro de cinema, adaptando a história, trazendo um novo olhar, que cruzasse pela narrativa sem que ela se perdesse, permitindo-se pensar, refletir e questionar o mundo multicultural, complexo e confuso em que vivemos hoje. Nesse processo de escolhas, os alunos demonstraram preferência pelos contos "A cartomante", "O Alienista", "Pai contra mãe", "Conto de Escola", "O espelho", porque, segundo eles, continuam atuais e tratam de questões que dizem respeito à essência humana: relações de poder, livre arbítrio, condicionamento social, relações interpessoais e introspectivas, falta de empatia. Essas percepções, discutidas com e entre os alunos, durante e após as leituras, retratam, pelo discurso e a partir do como se de Iser (1979), o olhar dos adolescentes sobre si e o outro, sobre a sociedade de que fazem parte.

A fim de instrumentalizar os estudantes no que diz respeito às especificidades de um roteiro, assistiu-se a trechos do filme "Cidade de Deus", fazendo-se comparações entre a história lida (roteiro do filme) e a assistida, assim como se analisou a linguagem específica de cada gênero. Concluída essa etapa, os alunos criaram os seus próprios roteiros.

Nesse processo de criação, o texto literário apresenta face dupla: a leitura-escritura, já que a adaptação da linguagem literária para a cinematográfica amplia diversas formas de conhecimento, utilizando-se da palavra e da imagem como ferramentas de criação dos roteiros que, por sua vez, também se transformam em objeto de leitura. Ademais, mais uma vez, a própria produção torna-se fonte de fruição da leitura, pois os roteiros, após concluídos, são lidos e ouvidos pelos colegas.

Agora, de alunos ouvintes de histórias, passaram a contadores das "suas" histórias. Trata-se de mais um momento de muitas trocas, pois além de o aluno "contar" o seu roteiro para os colegas, também divide um pouco da sua experiência com a leitura das narrativas do escritor Machado de Assis, explica por que produziu aquela história, quais as semelhanças e as diferenças com a obra machadiana, por que determinado texto foi escolhido, enfim, divide a experiência de leitor e de escritor com os colegas.

Após as apresentações, passou-se a pensar na gravação dos roteiros. Em grupos, os alunos decidiram quais seriam gravados, quem seriam os atores, editores, diretores, maquiadores, figurinistas... Todos participam de alguma forma com aquilo que sabem ou que gostariam de fazer/aprender; são encontros de muita discussão, de "apoderar-se" do texto e, ainda, de sugerir adaptações ao roteiro para que ele realmente possa ser gravado.

Anteriormente às filmagens, os alunos foram convidados a participar de workshops ${ }^{10}$ de filmagem, direção, edição, fotografia, cenário, maquiagem, figurino, os quais foram organizados e ministrados por participantes do Projeto no ano anterior e profissionais convidados da comunidade, no intuito de compreenderem um pouco melhor os bastidores das câmeras e, assim, sentirem-se mais seguros na produção dos seus curtas. Seguem alguns registros (Fotos 3 e 4) desses momentos.

\footnotetext{
10 Em 2018, aconteceram os seguintes workshops: Cleópatra: maquiagem, figurino e cenário; O mordomo da Casa Branca: direitos humanos; Literature and movies - Edgar Allan Poe Horror Stories; O segredo dos seus olhos: enxergar através da lente; Janela indiscreta: ângulos e lentes; De volta para o futuro: efeitos especiais; Psicose: terror, suspense e horror; Star Trek: uma jornada pela história do cinema; Mamma Mia: expressão corporal e atuação no cinema; Hannibal: psicopatologia: ficção x realidade; Senhor dos anéis: RPG e Cosplay; O riso dos outros: como fazer comédia?; A Vila: música no cinema; Aspectos técnicos e produção: prática de filmagem.
} 


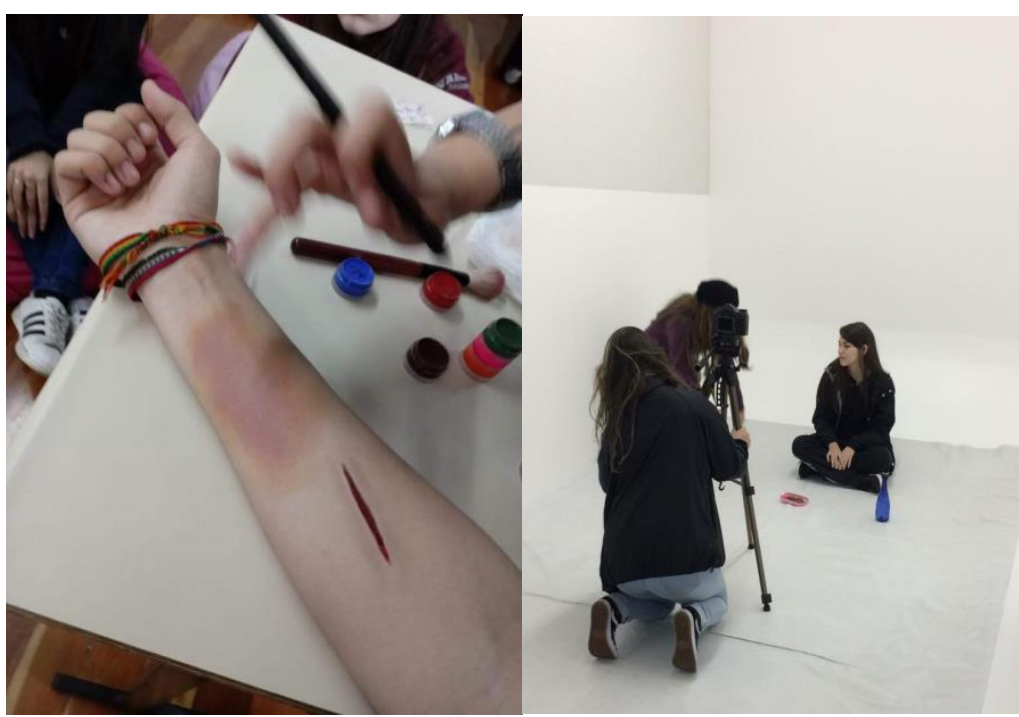

Fotos 3 e 4 - Workshops

Fonte: As autoras

Nesses momentos, novamente, volta-se aos textos para a produção das fichas de gravação com anotações importantes que conduzirão os trabalhos. Aqui, mais uma vez, é possível depreender, pelo discurso, aspectos axiológicos, seja na escolha dos atores, dos objetos que dão mais significado ao cenário, do estilo da roupa, da maneira de caminhar, da mania de algum personagem, tudo tem algo a dizer.

Após organizarem figurinos, cenários, estudarem os textos, os ângulos, é chegada a hora da filmagem. Durante uma semana, cada um, desempenhando seu papel: diretor, ator, câmera, figurinista, cenógrafo, editor, sonoplasta, ocupa diferentes espaços, tanto na escola quanto externos, para a gravação dos curtas. São horas intensas de trabalho colaborativo, em que grupos de adolescentes estão mergulhados em seu mundo de papel, vivendo-no como se fosse real. Aquele Projeto timidamente iniciado em 2002 agora é da escola e as filmagens acontecem nos turnos de aula, ou seja, na semana das filmagens, a aula é dirigida e organizada pelos alunos, que indicam o tempo, o lugar, que dão o tom, o ritmo e os passos a serem seguidos, no seu compasso... Quem decide se a cena deve ser regravada, se a interpretação ficou boa, se a luz está adequada, se deve haver silêncio ou não, são os alunos. Seguem algumas imagens (Fotos 5 e 6 ) desses momentos.

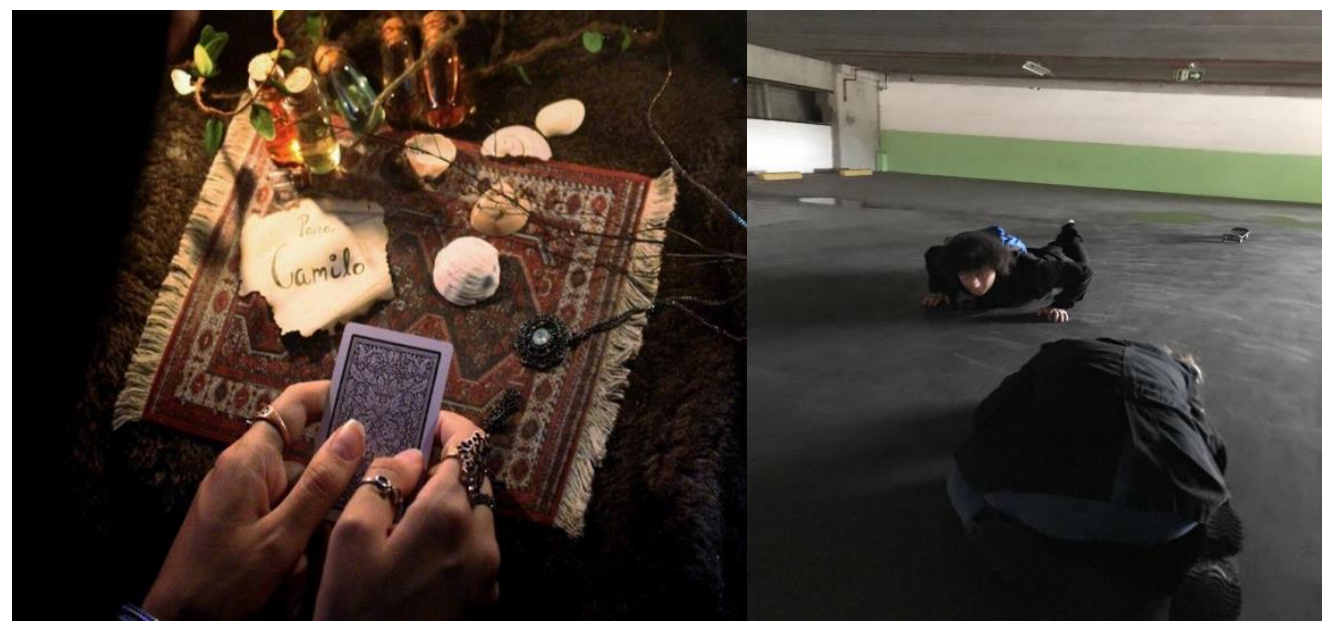

Fotos 5 e 6 - Cenas das filmagens

Fonte: As autoras 
Os curtas ficam prontos duas semanas depois e têm em média dez minutos de duração. Em 2018, participaram diretamente do Projeto 120 alunos, que, após se apoderarem do universo machadiano, produziram 14 curtas $^{11}$, quais sejam: Trapped, baseado em "O Alienista"; Bela mulher, baseado em "Pai contra mãe"; Verônica, baseado em "O Alienista"; Ela, baseado no poema "Ela"; Paranoia, baseado em "O Alienista"; Toc, baseado em "O Alienista"; Contra o espelho, baseado em "O Espelho"; A obra tem que continuar, baseado em "A Cartomante"; Entre conflitos e alucinações, baseado em "O Alienista"; Dead line, baseado em "O Medalhão"; Heterotopia, baseado em "Memórias póstumas de Brás Cubas"; Ana, baseado em "O Alienista" e "O bilhete"; Do outro lado, baseado em "Papéis Avulsos"; Nostalgia, baseado em "O Alienista". Seguem, para fins de exemplificação, alguns banners (Fotos 7 e 8) produzidos pelos alunos para divulgação dos seus curtas.

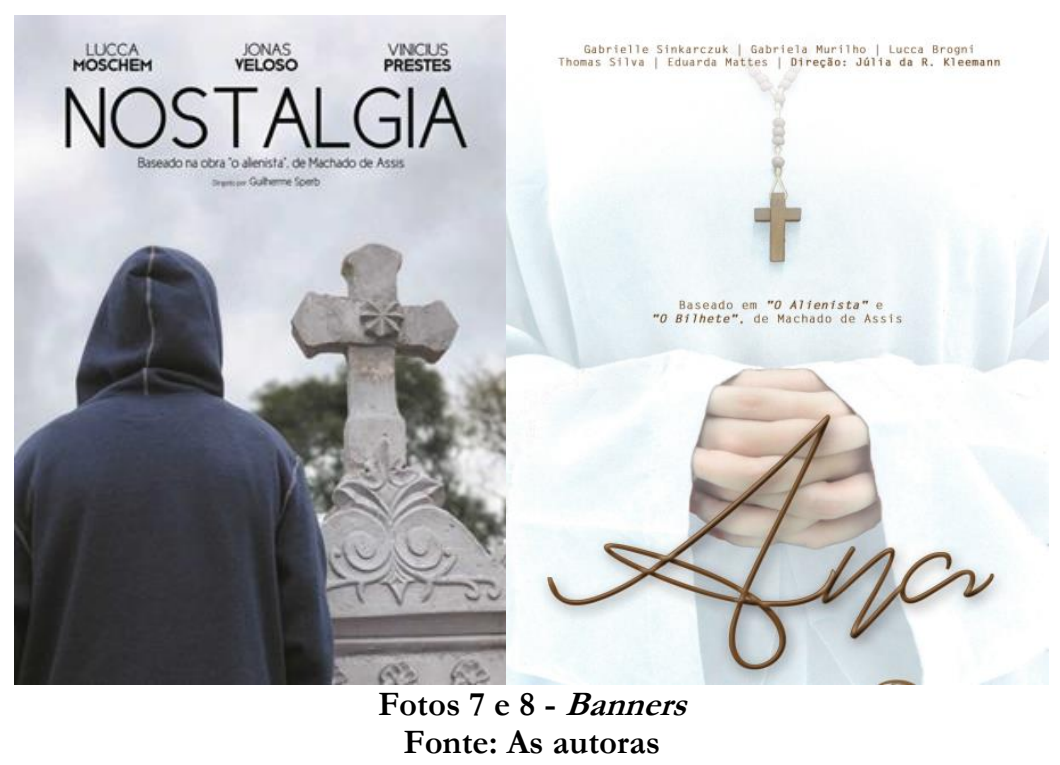

Muito mais que histórias, os produtos trazem consigo o olhar de uma geração, sobre si e o outro, seus hábitos culturais, seus posicionamentos ideológico-políticos, seus traços identitários, seus sonhos e utopias, compartilhados, em uma noite de estreia, com a comunidade escolar, que, por sua vez, mais que assistir aos filmes, tem a oportunidade de conhecer um pouco mais sobre a sua juventude. Após essa noite, na escola, organizam-se diferentes sessões, em diferentes horários, para compartilhamento dos curtas e seu processo de produção. Na Feira do Livro da cidade, nos últimos anos, os curtas também têm tido presença garantida. Na ocasião, os alunos compartilham com colegas de outras escolas suas produções e, ainda, têm a possibilidade de discutir pontos de vista sobre si e a sociedade, seja comparando os curtas com a obra machadiana, seja analisando os curtas entre si.

Ao transformar o roteiro em um curta-metragem, permite-se a circulação mais efetiva do produto entre os alunos e a comunidade escolar, além de promover a discussão crítica de temas próprios da adolescência, que são trazidos juntamente com os temas machadianos, como: violência, drogas, relacionamentos, família, morte, vida... A produção audiovisual, ao longo desses anos de Projeto, tem sido fundamental na divulgação e na apropriação dos textos literários.

\section{CONSIDERAÇÕES FINAIS}

As leituras e releituras realizadas de contos de Machado de Assis trazem ao leitor do século

11 Os curtas produzidos em 2018 estão disponíveis em https://www.youtube.com/channel/UCnbxAHjrEbaMXN6qPPQ4S8g. O público tem demonstrado preferência pelo curta "Ela". 
XXI a possibilidade de, pela literatura, ter contato com posições axiológicas de outra época. Os alunos têm, ainda, a possibilidade de estabelecer relações com a atualidade, de refletir sobre a língua e suas variantes, como forma de expressão e identidade dos grupos sociais e da época em foco. Durante os anos do Projeto, os alunos têm-se mostrado muito mais sensíveis à leitura literária e a ideia de "leitura difícil", geralmente atribuída às obras de Machado de Assis, por exemplo, vem dando lugar à compreensão do caráter universal dos temas tratados nos textos lidos, os quais oportunizam a reflexão sobre a identidade de cada jovem. Essas construções, contudo, só ocorrem porque se investe e se concebe o poder transformador da leitura literária, que precisa de uma escola e de professores que entendem ser possível fazer a diferença por meio de ações planejadas em que os conflitos humanos sejam postos em cena e discutidos.

Uma prática significativa torna possível aos alunos-leitores-criadores compreenderem o universo literário e penetrá-lo com mais intensidade e eficiência. Sendo assim, a distância que possa haver entre o texto e o leitor passa a ser um desafio e não um motivo para o afastamento. No caso do Ensino Médio, os adolescentes buscam formar e fortalecer suas novas identidades, numa faixa etária em que o infantil já não serve mais, porém, sem alcançar ainda o mundo adulto em toda sua extensão. Projetos pedagógicos como o relatado, que promovam a participação ativa, crítica e criativa dos jovens, vão ao encontro dessa premissa e favorecem a diversidade, a aprendizagem significativa, colocando o professor como mediador, divulgador e revitalizador da literatura.

Além disso, vale considerarmos a relevância do conto como um gênero literário a ser oferecido aos alunos, dada sua densidade e brevidade, marcas características desse texto que mobilizam o leitor. Especialmente no Ensino Médio, quando os interesses e as atenções dos alunos voltam-se, de forma especial, aos inúmeros estímulos do mundo, concorrendo com o que acontece na escola, os contos, pelas características destacadas, são alternativas ideal para a leitura literária mediada. Os flagrantes da vida humana expostos em um texto breve, que pode ser lido em um espaço curto de tempo - demanda escolar contemporânea - justificam sua escolha e importância para o projeto relatado e para qualquer outro que busque o enriquecimento da leitura literária e uma mediação efetiva. Os contos podem ser pensados e aproveitados por nós como recortes breves da vida, nos quais os indivíduos narrados representam o universo humano, a partir dos quais tomamos conhecimento de nós mesmos e do mundo.

Trata-se, pois, de um Projeto que tem contribuído para a formação do leitor jovem, que tem contato com diferentes perspectivas do narrar e a possibilidade de exercer autoria, ao, por exemplo, atualizar a história, significá-la para o tempo presente. Essa vivência sinaliza um modo oportuno de escolarização da literatura, em que a leitura do texto não é pretexto, mas a essência, é arte, é conhecimento, é fruição. Ademais, vai ao encontro de habilidades indispensáveis no século XXI, como criatividade, cooperação, autoria, protagonismo, autonomia, ao possibilitar tanto a escolha dos contos a serem lidos como qual seria atualizado, roteirizado, além de, no processo de construção dos curtas, cada aluno se envolver e escolher o papel a desempenhar, conforme suas preferências e competências. Por fim, também é importante considerar, pela perspectiva do diálogo entre as áreas, a relevância da ação articulada dos saberes que estão no currículo e a dinamicidade gerada, evidenciando a emergência de novos paradigmas na produção de conhecimentos e na sua construção já a partir da escola. Nesse sentido, considerando aquele que é o mediador desse processo, o professor, tem aí a possibilidade de, a cada ano, com novos alunos, em novos contextos, reinventar-se e, assim, ressignificar seu fazer, sua ação pedagógica.

\section{REFERÊNCIAS}

BRUNER, Jerome. Realidade mental, mundos possiveis. Porto Alegre: Artmed, 1997.

CALVINO, Italo. Por que ler os clássicos. Tradução Nilson Moulin. São Paulo: Companhia das Letras, 1993. 
CANDIDO, Antonio. Vários escritos. 3. ed. São Paulo: Duas Cidades, 1995.

CERTEAU, Michel de. A invenção do cotidiano. Tradução de Ephraim Ferreira Alves. 7. ed. Petrópolis: Vozes, 1994.

COSSON, Rildo. Letramento literário: teoria e prática. São Paulo: Contexto, 2006.

DIXON, Paul. Os contos de Machado de Assis: mais do que sonha a filosofia. Porto Alegre: Movimento, 1992.

FREIRE, Paulo. Pedagogia da autonomia: saberes necessários à prática educativa. São Paulo: Paz e Terra, 1997.

GLEDSON, John. Por um novo Machado de Assis: ensaios. São Paulo: Companhia das Letras, 2006.

GOTLIB, Nádia Batella. Teoria do conto. 11. ed. São Paulo: Ática, 2006.

ISER, Wolfgang. A interação do texto com o leitor. In: JAUSS, H.R. et al. A literatura e o leitor: textos de estética da recepção. Rio de Janeiro: Paz e Terra, 1979, p. 83-132.

- A indeterminação e a resposta do leitor na prosa de ficção. Tradução de Maria Angela Aguiar. Cadernos do Centro de Pesquisas Literárias da PUCRS - Série Traduções, Porto Alegre, v. 3, n. 2, mar. 1999.

JAUSS, Hans Robert. A bistória da literatura como provocação à teoria literária. São Paulo: Ática, 1994.

LAJOLO, Marisa. Tecendo a leitura. In: Do mundo da leitura para a leitura do mundo. São Paulo: Ática, 2008. p. 104-109.

LARROSA, Jorge. La experiência de la lectura: estudos sobre literatura y formación. México: Fondo de Cultura Económica, 2003.

MANGUEL, Alberto. Uma história da leitura. São Paulo: Companhia das Letras, 1997.

PETIT, Michele. Os jovens e a leitura: uma nova perspectiva. Tradução de Celina Olga de Souza. São Paulo: Ed. 34, 2008.

SÁ REGO, Enylton José de. O calundu e a panacéia: Machado de Assis, a sátira menipeia e a tradição luciânica. Rio de Janeiro: Forense Universitária, 1989.

SEARLE, John Rogers. O estatuto lógico do discurso ficcional. In: . Expressão e significado: estudo das teorias dos atos da fala. Tradução de Ana Cecília G. A. de Camargo e Ana Luiza Marcondes Garcia. 2. ed. São Paulo: Martins Fontes, 2002.

SOARES, Magda. Ler, verbo transitivo. In: PAIVA, Aparecida et al. (Orgs.). Leituras literárias: discursos transitivos. Belo Horizonte: Autêntica, 2005. 